\title{
EFEITO DA OMISSÃO DE MACRONUTRIENTES NO CRESCIMENTO, NOS SINTOMAS DE DEFICIÊNCIAS NUTRICIONAIS E NA COMPOSIÇÃO MINERAL EM GRAVIOLEIRAS (Annona muricata) ${ }^{1}$
}

\author{
MAGNALDA MARIA FERNANDES BATISTA ${ }^{2}$, ISMAEL DE JESUS MATOS VIÉGAS ${ }^{3}$, DILSON AUGUSTO CAPUCHO \\ FRAZÃO ${ }^{4}$, MARIA ALICE ALVES THOMAZ ${ }^{5}$ RITA DE CÁSSIA LEMOS DA SILVA ${ }^{6}$
}

\begin{abstract}
RESUMO - Com o objetivo de avaliar o efeito da omissão de macronutrientes no crescimento, nos sintomas de deficiências nutricionais e na composição mineral em gravioleiras, conduziu-se experimento em casa de vegetação, mediante a técnica do elemento faltante. O delineamento foi o inteiramente casualizado, com quatro repetições e sete tratamentos, sendo completo ( $\mathrm{N}, \mathrm{P}, \mathrm{K}, \mathrm{Ca}, \mathrm{Mg}, \mathrm{S}$ e micronutrientes) e com omissão individual de N, P, K, Ca, Mg e S. As omissões dos macronutrientes afetaram o crescimento em altura, diâmetro das plantas e produção de matéria seca, quando comparados ao tratamento completo. Com base nos teores em $\mathrm{g} / \mathrm{kg}$ dos macronutrientes nas folhas, encontraram-se os seguintes valores adequados nos tratamento completo e com omissão: $\mathrm{N}=14,70$ e 8,82; $\mathrm{P}=0,92$ e 0,47; $\mathrm{K}=12,35$ e 2,62; Ca = 14,11 e 3,44; $\mathrm{Mg}=3,59$ e 1,09; $\mathrm{S}=5,32$ e 2,30.
\end{abstract}

Termos para indexação: graviola, nutrição mineral.

\section{EFFECT OF MACRONUTRIENT OMISSION IN GROWTH, SYMPTOMS OF NUTRITIONAL DEFICIENCY AND MINERAL COMPOSITION IN SOURSOP PLANTS (Annona muricata)}

\begin{abstract}
This work had the objective of evaluating the effect of macronutrient omission in growth, symptoms of nutritional deficiency and mineral composition in soursop plants. It was carried out an experiment in greenhouse conditions, using the missing element technique. It was developed a randomized experiment with four repetition and seven treatments being completed ( $\mathrm{N}, \mathrm{P}, \mathrm{K}, \mathrm{Ca}$. Mg, S and micronutrients) and with the omission of N, P, K, Ca, Mg and S from a complete solution. Omissions related to all macronutrients affected plant growth in height, diameter and dry matter yield compared to the complete treatment. Based on the contents in $\mathrm{g} / \mathrm{kg}$ found in leaves, the levels to adequate (complete) and deficient nutrient were defined as following: $\mathrm{N}=14,70$ and 8,$82 ; \mathrm{P}=0,92$ and 0,$47 ; \mathrm{K}=12,35$ and 2,$62 ; \mathrm{Ca}=14,11$ and 3,44;
\end{abstract}

$\mathrm{Mg}=3,59$ and 1,09; $\mathrm{S}=5,32$ and 2,30, respectively.

Index terms: soursop, mineral nutrition

\section{INTRODUÇÃO}

A gravioleira (Annona muricata L) apresenta-se como uma das espécies de grande importância econômica para a fruticultura regional. Existe demanda crescente dos frutos, cujas qualidades organolépticas importantes possibilitam a utilização, tanto para consumo "in natura" quanto para o aproveitamento pela agroindústria. A gravioleira também possui propriedades utilizadas na medicina homeopática e na culinária caseira, sendo aproveitada sob as mais diversas formas. Neste contexto, a produção de fruteiras regionais, por ser oriunda, na sua grande maioria, do extrativismo ou do semi-extrativismo, ainda reflete o pouco conhecimento dos diferentes componentes que constituem o sistema de produção das culturas. A produção de fruteiras na Amazônia ainda é limitada pela carência de conhecimentos sobre os diversos segmentos dos sistemas de produção, sobretudo no que concerne a estudos sobre a nutrição mineral de plantas.

As técnicas de diagnose da fertilidade de solo costumam ser divididas em quatro grupos, tais como: análise química do solo, análise de plantas, métodos biológicos e diagnose visual. Esta pesquisa baseou-se na técnica da diagnose visual, a qual se fundamenta no fato de que as plantas, com deficiência de um determinado nutriente, apresentam sintomas característicos. O objetivo deste trabalho foi avaliar o crescimento, caracterizar a sintomatologia de deficiências de macronutrientes e a composição mineral de plantas de gravioleira.

\section{MATERIALEMÉTODOS}

O experimento foi conduzido em condições de casa de vege- tação da Embrapa Amazônia Oriental, Belém, Pará, no delineamento inteiramente casualizado, com quatro repetições e sete tratamentos: completo (N, P, K, Ca, Mg, S e micronutrientes) e com omissão de: N, P; $\mathrm{K} ; \mathrm{Ca} ; \mathrm{Mg}$ e S. Utilizaram-se sementes da cultivar Morada, considerada tolerante ao ataque das brocas dos frutos (Cerconota anonella Spp) e do tronco (Cratosomus dulis F). A solução nutritiva utilizada foi a de Bolle-Jones (1954) modificada. Utilizaram-se vasos de plástico com capacidade para $5 \mathrm{~L}$, contendo sílica lavada (tipo zero grossa). As plantas foram aclimatadas por um período de aproximadamente 75 dias, em solução nutritiva a diferentes diluições seqüenciadas. Após esse período, as plantas atingiram altura média de aproximadamente $30 \mathrm{~cm}$, quando foram submetidas aos tratamentos completo e com omissão dos macronutrientes, com solução nutritiva diluída a 1:1, até a manifestação dos sintomas de deficiência dos nutrientes omitidos. As soluções nutritivas foram fornecidas por percolação nos vasos, renovadas a intervalos de 15 dias. Diariamente, as soluções dos tratamentos eram fornecidas no período da manhã e drenadas no período da tarde, perfazendo oito horas. Teve-se, ainda, o cuidado de verificar diariamente o nível da solução nos frascos coletores, completando-se o volume para um litro, quando necessário, com adição de água destilada. Quando todos os sintomas de deficiência, referentes aos nutrientes estudados, se apresentaram bem definidos, as plantas foram coletadas e divididas em folha, caule e raiz. Em seguida, as amostras foram secas em estufa com circulação forçada de ar a $70{ }^{\circ} \mathrm{C}$, para a determinação do peso do material seco, procedendo-se, posteriormente, a moagem e análise química de macronutrientes, para a determinação dos teores de macronutrientes com base na metodologia descrita por Möller et al. (1997). Os dados de medições biométricas, produção de matéria seca e teores de macrontrientes foram analisados estatisticamente através da

\footnotetext{
${ }^{1}$ (Trabalho 164/2002). Recebido: 30/10/2002. Aceito para publicação: 03/07/2003. Pesquisa desenvolvida em parceria com a JICA e extraída da dissertação de mestrado pelo primeiro autor para obtenção do grau de mestre na FCAP.

${ }^{2}$ Eng. Agrôn., M.Sc., Faculdade de Ciências Agrárias do Pará, Caixa Postal 917, CEP 66077-530, Belém, Pará.

${ }^{3}$ Eng. Agrôn., D.Sc., Pesquisador da Embrapa Amazônia Oriental e Professor Visitante da FCAP. Caixa Postal 48, CEP 66.017-970, Belém, Pará, e-mail: ismael@cpatu.embrapa.br.

${ }^{4}$ Eng. Agrôn., D.Sc., Pesquisador da Embrapa Amazônia Oriental Caixa Postal 48, CEP 66.017-970, Belém, Pará, e-mail: dilson@ @patu.embrapa.br.

${ }^{5}$ Eng. Agrôn., M.Sc., da Fundação de Parques e Áreas Verdes de Belém, Funverde.

${ }^{6}$ Eng. Agrôn., M.Sc., Faculdade de Ciências Agrárias do Pará , Caixa Postal 917, CEP 66077-530, Belém, Pará.
} 
análise de variância e aplicado o teste Tukey, a 5\% de probabilidade, para a comparação das médias, de acordo com a metodologia descrita por Pimentel Gomes (1990). O efeito dos tratamentos foi avaliado pelo método de Percentagem de Suficiência ou Produção Relativa, segundo Raij (1991).

\section{RESULTADOS E DISCUSSÃO}

\section{Sintomas visuais de deficiências de macronutrientes Nitrogênio}

As plantas de graviola em solução nutritiva com omissão de nitrogênio manifestaram sintomas de deficiência do nutriente logo após o início dos tratamentos. Verificou-se, primeiramente, que as folhas mais velhas, a partir da região basal, perdiam gradualmente a coloração verde para uma tonalidade verde-pálida, distribuindo-se uniformemente no limbo, pecíolo e nervuras. O nitrogênio absorvido é facilmente distribuído na planta via floema, na forma de aminoácidos. Quando o suprimento é insuficiente, o nitrogênio das folhas velhas é mobilizado para os órgãos e folhas mais novas. Conseqüentemente, verificam-se sintomas de clorose nas plantas deficientes em nitrogênio, principalmente nas folhas velhas. A coloração amarelada está associada à menor produção de clorofila e com modificações na forma dos cloroplastos (Malavolta et al. 1997). Com a intensidade da deficiência, todas as folhas ficaram amareladas e sem brilho, ocorrendo queda prematura das folhas mais velhas. Observou-se, também, redução generalizada na altura e diâmetro do caule. Avilán (1975) e Silva et al. (1986), trabalhando com a gravioleira, e Piza Júnior (1988), com fruta-do-conde, observaram características semelhantes de deficiência de nitrogênio.

\section{Fósforo}

Os sintomas de deficiência de fósforo foram inicialmente observados nas folhas superiores, as quais se apresentaram em relação ao tratamento completo, mais estreitas, tamanho reduzido, bordos curvados e ápices para baixo. As folhas inferiores, paralelas ao caule, apresentaram coloração verde-clara. Plantas com deficiência em fósforo têm o seu crescimento retardado, devido afetar vários processos, como a síntese protéica e de ácidos nucléicos (Mengel \& Kirkby,1987). Na gravioleira, Avilán (1975) e Silva et al. (1986) observaram, com a omissão de fósforo, redução no porte da planta, em relação ao tratamento completo, com sintomas de deficiência inicialmente nas folhas inferiores, atingindo, em seguida, as folhas medianas e superiores, sendo, portanto, esses sintomas de deficiência de fósforo semelhantes aos obtidos nesta pesquisa.

\section{Potássio}

A deficiência de potássio caracterizou-se, inicialmente, com um esverdeamento intenso da folhagem, com pequena redução no tamanho das folhas novas. Nas folhas mais velhas, a partir do ápice, observou-se clorose marginal, avançando em direção à parte central por entre as nervuras, inicialmente de coloração verde-amarela, para posteriormente marrom, como conseqüência da necrose. Com a severidade da deficiência, ocorreram a queda das folhas basais e estabilidade no crescimento. Silva et al. (1986) constataram, também, em gravioleira, redução no tamanho das folhas jovens e, quando adultas, apresentaram bordos cloróticos e queda precoce das folhas. Avilán (1975) verificou, também, amarelecimento nos bordos, progredindo até a nervura central, de coloração alaranjada. Por ser o potássio ativador de numerosas enzimas, sua deficiência acarreta distúrbios em reações metabólicas de acumulação de compostos nitrogenados livres ou solúveis (Epstein, 1975)

\section{Cálcio}

A omissão de cálcio acarretou anormalidades visíveis nas folhas mais novas, percebendo-se, inicialmente, necrose ao longo da margem superior do ápice da folha, com o restante da folhagem apresentando verde normal. Esta necrose na folha apresentou-se "queimada" de coloração pardo-escura e enrolada sobre si mesma, com bordos recurvados para cima. A falta de cálcio é caracterizada pela redução do crescimento de tecidos meristemáticos, sendo observada, inicialmente, nas extremidades em crescimento e nas folhas mais jovens (Mengel \& Kirkby, 1987). Com a evolução dos sintomas, houve queda prematura das folhas, e as plantas sofreram redução no crescimento pela paralisação do desenvolvimento apical. No processo metabólico, o cálcio afeta a atividade de hormônios e de enzimas, como os que regulam a senescência e a abscisão das folhas e frutos (Malavolta, 1980; Mengel \& Kirkby, 1987; Marschner, 1986). Os sintomas observados por Avilán (1975), em gravioleira, também mostraram clorose em torno das margens e entre as nervuras principais e, posteriormente, as áreas afetadas necrosaram.

\section{Magnésio}

Os primeiros sintomas de deficiência de magnésio foram observados inicialmente nas folhas mais velhas da parte mediana da planta, com o aparecimento de leve amarelecimento ao longo da nervura principal. A nervura principal e as margens laterais das folhas mantiveram-se verdes. À medida que aumentava a intensidade de deficiência de magnésio, a faixa amarelada tornava-se totalmente alaranjada, ocasionando a abscisão precoce das folhas de gravioleira. Percebeu-se, também, que a altura da planta foi reduzida com a omissão de magnésio. Sintomas semelhantes, também, foram observados por Avilán (1975) e Silva et al. (1986) em gravioleira, em que a deficiência provocou o aparecimento de uma clorose internerval que começou ao lado da nervura central e avançou, progressivamente, até os bordos das folhas. $\mathrm{O}$ magnésio é muito móvel no floema e, portanto, redistribui-se facilmente nas folhas e tecidos mais velhos para regiões de maiores exigências, como os meristemas e órgãos de reserva (Epstein, 1975); logo, os sintomas de deficiência aparecem inicialmente nas folhas mais velhas, fato constatado nesta pesquisa.

\section{Enxofre}

As plantas com carência de enxofre apresentaram coloração verde nas folhas novas, em um tom menos claro em relação às folhas do tratamento completo, com nervuras mais pálidas em relação ao limbo, de tamanho menor, caule mais delgado, crescimento reduzido em relação ao completo. Os sintomas observados por Avilán (1975), em plantas de gravioleira, são similares aos observados nesta pesquisa, pois os mesmos caracterizaram-se por apresentar folhas superiores com deformações de tamanho e de coloração inicialmente verde-pálida, tornando-se posteriormente cloróticas, tendo as folhas inferiores apresentado aparência normal. Entretanto, Silva et al. (1986) não observaram sintomas característicos da deficiência de enxofre em gravioleiras, porém as mudas cultivadas em solução com omissão de enxofre pelos citados pesquisadores foram visivelmente menores do que as cultivadas em solução completa.

Efeito da omissão dos macronutrientes sobre a altura das plantas, diâmetro do caule, produção de matéria seca e crescimento relativo.

Os resultados referentes à altura das plantas, diâmetro do caule, produção de matéria seca e crescimento relativo, em função dos tratamentos, como indicadores de desenvolvimento, encontram-se na Tabela 1. Verifica-se, pelos resultados, que as omissões de todos os macronutrientes afetaram o crescimento em altura das plantas, sendo a omissão individual de nitrogênio com $37 \mathrm{~cm}$, omissão de cálcio com 51 $\mathrm{cm}$ e de fósforo com $58 \mathrm{~cm}$ as mais afetadas, quando comparadas com o tratamento completo, cuja altura foi de $174 \mathrm{~cm}$. Avilán (1975) verificou, em gravioleira, que os tratamentos com omissão de nitrogênio e fósforo foram os que mais limitaram o crescimento em solução nutritiva, concordando em parte com os resultados da presente pesquisa. Com relação ao diâmetro do caule, a exemplo do ocorrido com a altura de planta, constatou-se que todos os tratamentos com as omissões individuais limitaram o crescimento, quando comparados ao completo (Tabela 1). Os tratamentos que mais afetaram este parâmetro, foram os que apresentaram omissão de nitrogênio com 5,90 mm, cálcio com 7,07 $\mathrm{mm}$ e fósforo com $8,20 \mathrm{~mm}$, em relação ao tratamento completo, de $20,85 \mathrm{~mm}$. 
TABELA 1- Altura $(\mathrm{cm})$ e diâmetro do caule $(\mathrm{mm})$ das plantas de gravioleira, em função dos tratamentos.

\begin{tabular}{lcc}
\hline Tratamentos & Altura $(\mathrm{cm})$ & Diâmetro $(\mathrm{mm})$ \\
\hline Completo & $174 \mathrm{a}$ & $20,85 \mathrm{a}$ \\
Omissão de N & $37 \mathrm{~d}$ & $5,9 \mathrm{~d}$ \\
Omissão de P & $58 \mathrm{~cd}$ & $8,2 \mathrm{~cd}$ \\
Omissão de K & $75 \mathrm{c}$ & $9,74 \mathrm{c}$ \\
Omissão de Ca & $51 \mathrm{~cd}$ & $7,07 \mathrm{~cd}$ \\
Omissão de Mg & $70 \mathrm{c}$ & $8,87 \mathrm{c}$ \\
Omissão de S & $124 \mathrm{~b}$ & $16,67 \mathrm{~b}$ \\
\hline CV (\%) & 15,24 & 10,38 \\
\hline
\end{tabular}

*Médias seguidas pela mesma letra nas colunas não diferem entre si, ao nível de $5 \%$ de probabilidade, pelo teste de Tukey.

A produção de matéria seca das raízes, caule, folhas, total e do índice de "crescimento relativo", de plantas submetidas aos diferentes tratamentos, é apresentada na Tabela 2. Nas raízes, todos os tratamentos com omissão de nutrientes limitaram a produção de matéria seca. $\mathrm{Na}$ omissão de enxofre, embora tenha apresentado maior produção que os demais, ainda assim, foi significativamente menor que o tratamento completo. Quanto à produção de matéria seca do caule, verifica-se que os tratamentos com omissão de potássio e enxofre apresentaram maior produção em relação aos demais tratamentos, mas significativamente menor que o completo (Tabela 2). Com relação à produção de matéria seca das folhas, todos os tratamentos com omissão foram limitantes, com exceção da omissão de enxofre, que proporcionou maior produção que o tratamento completo, embora sem diferirem estatisticamente entre si (Tabela 2). As menores produções de matéria seca das folhas foram registradas nos tratamentos com omissão de nitrogênio, com 1,63 g/ planta; de cálcio, com 2,68 g/planta; e de fósforo, com 2,86 g/planta. Verificou-se que o tratamento completo apresentou produção de matéria seca total de 127,94 g/planta, significativamente superior aos demais tratamentos. Os tratamentos que mais afetaram a produção da matéria seca total, a exemplo dos resultados obtidos com as variáveis altura das plantas e diâmetro do caule, foram as omissões de nitrogênio com 7,49 g/ planta, de cálcio com 10,42 g/planta e de fósforo com 14,42 g/planta, quando comparados com o padrão de 127,94 g/planta. Finalmente, a ordem decrescente, em que a ausência de um determinado elemento influenciou na diminuição da produção total de matéria seca das plantas de graviola, foi a seguinte: nitrogênio > cálcio > fósforo > magnésio > potássio $>$ enxofre. $\mathrm{O}$ crescimento relativo $(\mathrm{CR})$ obedeceu à seguinte ordem decrescente, em relação aos tratamentos: completo > enxofre > potássio > magnésio > fósforo > cálcio > nitrogênio, deduzindo-se, dessa maneira, que o desenvolvimento da planta, durante o período experimental, foi menos prejudicado pela carência de enxofre, com redução de $34 \%$ da matéria seca, porém mais afetado pelo nitrogênio, com redução de $94 \%$ da matéria seca.

Os resultados dos teores de macronutrientes correspondentes a cada tratamento são apresentados na Tabela 3. Verificou-se que os teores $(\mathrm{g} / \mathrm{kg})$ dos macronutrientes nas folhas do tratamento completo e com omissão dos nutrientes foram, respectivamente: $\mathrm{N}=14,70-8,82$;
$\mathrm{P}=0,92-0,47 ; \mathrm{K}=12,35-2,62 ; \mathrm{Ca}=14,11-3,44 ; \mathrm{Mg}=3,59-1,09 ; \mathrm{S}=5,32$ $-2,30$. Os teores de macronutrientes das plantas do tratamento completo obedeceram à seguinte ordem, nas raízes: $\mathrm{N}>\mathrm{S}>\mathrm{K}>\mathrm{Ca}>\mathrm{Mg}>\mathrm{P}$, no caule: $\mathrm{K}>\mathrm{N}>\mathrm{Ca}>\mathrm{S}>\mathrm{Mg}>\mathrm{Pe}$ nas folhas: $\mathrm{N}>\mathrm{Ca}>\mathrm{K}>\mathrm{S}>\mathrm{Mg}>\mathrm{P}$. Com base nos teores dos macronutrientes nas folhas do tratamento completo e dos com omissão (deficiente), pode-se obter a variação de teores destes nutrientes na gravioleira (Tabela 3). Os teores foliares de cálcio e enxofre do tratamento completo são superiores aos considerados como adequados por Silva et al. (1986), também obtidos em condições de casa de vegetação, e os de nitrogênio, fósforo e potássio inferiores, enquanto os de magnésio são praticamente iguais. Gazel Filho (1994), em condições de cerrado do Amapá, obteve no genótipo Morada, de um ano de idade, teor de nitrogênio de $20,2 \mathrm{~g} \mathrm{~kg}^{-1}$, fósforo de $1,4 \mathrm{~g} \mathrm{~kg}$, potássio de 14,9 $\mathrm{gkg}^{-1}$, os quais são $27 \%, 34 \%$ e $21 \%$, respectivamente, superiores aos considerados nesta pesquisa. Por outro lado, os teores de cálcio e magnésio sugeridos como adequados neste trabalho são superiores aos obtidos por Gazel Filho (1994), em 13,5\% e 88,9\%, respectivamente. Esses resultados conflitantes entre os teores de macronutrientes adequados para a gravioleira podem ser explicados em função da cultivar, da solução nutritiva, com maior ou menor concentração de sais, tempo de duração do trabalho e de renovação da solução nutritiva, no caso de experimentos conduzidos em casa de vegetação, e nos conduzidos em condições de campo como conseqüência dos fatores que atuam e interagem até o momento da coleta da parte da planta para análise, podendo-se citar clima, solo, práticas culturais, etc.

TABELA 3 - Teores de macronutrientes $(\mathrm{g} / \mathrm{kg}$ ) nas diversas partes de gravioleira, em função dos tratamentos.

\begin{tabular}{lccr}
\hline Tratamento & Raiz & Caule & Folha \\
\hline Completo & 28,35 & 6,02 & 14,70 \\
& 1,8 & 0,95 & 0,92 \\
& 9,62 & 9,25 & 12,35 \\
& 5,41 & 5,40 & 14,11 \\
& 2,21 & 1,21 & 3,59 \\
& 26,48 & 4,88 & 5,32 \\
Omissão de N & & & \\
Omissão de P & 8,67 & 5,07 & 8,82 \\
Omissão de $\mathrm{K}$ & 0,65 & 0,37 & 0,47 \\
Omissão de Ca & 2,52 & 1,95 & 2,62 \\
Omissão de $\mathrm{Mg}$ & 1,48 & 1,38 & 3,44 \\
Omissão de $\mathrm{S}$ & 0,69 & 1,09 & 1,09 \\
& 2,12 & 0,86 & 2,30 \\
\hline
\end{tabular}

\section{CONCLUSÕES}

1) A omissão de $\mathrm{N}, \mathrm{P}, \mathrm{K}, \mathrm{Ca}, \mathrm{Mg}$ e $\mathrm{S}$, na solução nutritiva, resulta em alterações morfológicas, traduzidas como sintomas característicos de deficiência nutricional de cada nutriente em gravioleira.

2) As omissões de macronutrientes promovem diminuição no crescimento e produção de matéria seca em gravioleira, quando comparadas ao tratamento completo.

TABELA 2 - Produção de matéria seca da folha, caule, raiz e total (g/planta), crescimento relativo (CR) de gravioleiras, em função dos tratamentos.

\begin{tabular}{lccccc}
\hline Tratamento & Raiz & Caule & Folha & Total & \multicolumn{1}{c}{ CR } \\
\hline Completo & $42,75 \mathrm{a}$ & $58,75 \mathrm{a}$ & $21,00 \mathrm{a}$ & $127,94 \mathrm{a}$ & 100 \\
Omissão de N & $3,47 \mathrm{c}$ & $2,39 \mathrm{~d}$ & $1,63 \mathrm{~d}$ & $7,49 \mathrm{e}$ & 6 \\
Omissão de P & $5,41 \mathrm{c}$ & $5,72 \mathrm{~d}$ & $2,86 \mathrm{~cd}$ & $14,05 \mathrm{ed}$ & 11 \\
Omissão de K & $8,54 \mathrm{c}$ & $12,32 \mathrm{c}$ & $10,61 \mathrm{~b}$ & $30,48 \mathrm{c}$ & 25 \\
Omissão de Ca & $4,09 \mathrm{c}$ & $3,90 \mathrm{~d}$ & $2,68 \mathrm{~d}$ & $10,42 \mathrm{ed}$ & 8 \\
Omissão de $\mathrm{Mg}$ & $6,98 \mathrm{c}$ & $6,48 \mathrm{~d}$ & $7,94 \mathrm{cb}$ & $21,40 \mathrm{~cd}$ & 17 \\
Omissão de S & $19,86 \mathrm{~b}$ & $35,70 \mathrm{~b}$ & $25,37 \mathrm{a}$ & $80,93 \mathrm{~b}$ & 66 \\
\hline CV $(\%)$ & 38,73 & 13,90 & 22,63 & 12,80 &
\end{tabular}

Médias seguidas pela mesma letra nas colunas não diferem entre si, ao nível de 5\% de probabilidade, pelo teste de Tukey. 


\section{REFERÊNCIASBIBLIOGRÁFICAS}

AVILÁN, L.R. Efecto de la omisión de los macronutrientes en el desarollo y composición química de la guanábana (Annona muricata L.) cultivada en soluciones nutritivas. Agronomia Tropical, Maracay, v.25, n. 1, p 73-79, 1975.

BOLLE-JONES, E. W. Nutrition of (Hevea brasiliensis). II. Effects of nutrient deficiencies on growth, chlorophyll, rubber and contents of Tjirandji seedlings. Journal of Rubber Research Institute of Malaya, v. 14, n. 2, p. 209, 1954.

EPSTEIN, E. Nutrição mineral de plantas, princípios e perspectivas. São Paulo: Universidade de São Paulo, 1975. 341p.

GAZEL FILHO, A. B.; CARVALHO, A. C. de A. \& MENEZES, A. J. E. A de. Teores de macronutrients em folhas de gravioleira. Revista Brasileira de Fruticultura, Cruz das Almas, v.16, n.2, p.121-124, set. 1994.

MALAVOLTA, E. Elementos de nutrição mineral de plantas. São Paulo: Ceres, $1980.251 \mathrm{p}$.

MALAVOLTA, E.; VITTI, G. C.; OLIVEIRA, S. A. Avaliação do estado nutricional das plantas : princípios e aplicações. 2.ed. Piracicaba: POTAFOS, 1997.319p.

MENGEL, K. ; KIRKBY, E.A. Principles of plant nutrition. Bern, Intern. Potash Institute, 1987.687p.
MARSCHNER, H. Mineral nutrition of higher plants. London: Academic Press, 1986. 674p.

MENGEL, K. \& KIRKBY, E.A. Principles of plant nutrition. Bern, Intern. Potash Institute, 1987. 687p.

MÖLLER, M. M.; VIÉGAS, I. de J. M.; MATOS, A. de O.; PARRY, M.; Análise de tecido vegetal: manual de laboratório. Belém: EmbrapaCPATU, 1997. 32p. (Documento, 92).

PIMENTEL GOMES, F. Curso de estatística experimental. Piracicaba: Nobel, 1990.468p.

PIZA JÚNIOR, C. de T. Fruta-do-conde (Annona squamosa L): manual técnico da cultura. Campinas, CATI, 1988. p. 239-243.

RAIJ, B. VAN. Fertilidade do solo e adubação. Piracicaba: Agronômica. Ceres/POTAFOS, 1991.343p.

SILVA, A.Q. da.; SILVA, H.; ROQUE, M. L. \& MALAVOLTA, E. Nutrição Mineral da Graviola (Annona muricata L). I. Sintomas de carência nutricionais. In: CONGRESSO BRASILEIRODE FRUTICULTURA, 8. Brasília, DF, 1986. Anais... Brasília, SBF, 1896. n., v. 2, p. 297-303.

VIÉGAS, I. de J. M. Crescimento do dendezeiro (Elaeis guineensis Jacq.) concentração, conteúdo e exportação de nutrientes nas diferentes partes de plantas com 2 a 8 anos de idade, cultivadas em Latossolo amarelo distrófico, Tailândia - Pará., 217p., Tese (Doutorado) Escola Superior de Agricultura "Luiz de Queiroz", Universidade de São Paulo, Piracicaba, 1993. 